\title{
BREVES CONSIDERACIONES SOBRE LAS ORIENTACIONES POLÍTICO-CRIMINALES DEL TRATAMIENTO DE LA DELINCUENCIA JUVENIL ${ }^{1}$
}

\author{
Brief observations about underage criminal policy orientations
}

\section{Julio César KALA}

\section{Sumario:}

I. Consideraciones previas. II. En torno a la política criminal. III. Justicia penal juvenil. IV. Consideraciones finales. V. Fuentes.

Resumen: La respuesta institucional frente a los menores de edad que actualizan conductas contempladas en la ley penal se ha orientado, en general, en términos similares a la respuesta penal dirigida a los adultos, pero sin las garantías constitucionales que éstos han conquistado. Sólo recientemente con el modelo de responsabilidad juvenil se ha cobijado a los jóvenes con las garantías inherentes a un sistema de justicia penal democrático, sin embargo, persistir en qué el criterio de responsabilidad juvenil esté contemplado en el ámbito penal genera problemas de consistencia interna y externa de ésta orientación político-criminal.

Palabras clave: Política criminal, tutelarismo, responsabilidad

Abstract: The institutional response to underage criminal has focused generally on terms similar to the penal response directed at adults, but without these constitutional guarantees. Only recently with the model of Juvenile Liability to young people sheltered with the same guarantees inherent in a democratic system, nevertheless the criteria of Juvenile Liability as provided in criminal law generates internal and external problems of judicial consistency.

Keywords: Criminal policy, tutelary, liability

\section{CONSIDERACIONES PREVIAS}

El Sistema Integral de Justicia para Adolescentes mexicano ${ }^{3}$ es una versión del modelo contemporáneo de responsabilidad penal juvenil. Por dirigir la reacción institucional referida

\footnotetext{
${ }^{1}$ Agradezco a los miembros del Programa de Investigaciones Jurídicas de la División de Derecho Política y Gobierno de la Universidad de Guanajuato el tiempo que destinaron para leer el escrito previo, así como las observaciones, las acotaciones y las sugerencias que realizaron, lo que permitió resolver algunas de sus inconsistencias.

${ }^{2}$ Profesor del Departamento de Derecho, Universidad de Guanajuato, México. Miembro del Cuerpo Académico Ciencia Penal, Estado de Derecho y Derechos Humanos.

3 El 12 de diciembre del 2005 en el Diario Oficial de la Federación se publicó el decreto que reforma [...] el párrafo cuarto y se adicionan los párrafos quinto y sexto y se recorren en su orden los últimos párrafos del Ar-
} 
a los jóvenes en conflicto con la ley penal forma parte de la política criminal, ${ }^{4}$ no obstante, que ésta se ha desarrollado ${ }^{5}$ referido preponderantemente a la adultez. ${ }^{6}$

En este sentido, valga subrayar el carácter público de la política criminal, que por ser una política de Estado requiere, formalmente, congruencia con los principios del modelo político jurídico de éste adopte. En occidente se ha acogido, por lo menos nominalmente, al Estado de derecho como paradigma, lo que implica que el aparato público que le da vida, en caso de ruptura de la norma actúe ejerciendo la violencia mínima indispensable para reaccionar contra el infractor en el despliegue legítimo de la violencia institucional en el ejercicio del ius puniendi, dado que el Estado como formalización jurídica del pacto político, surge para proteger a sus asociados de la violencia y para brindarles el mayor bienestar posible, por ello, la disminución de la violencia y de sus efectos es uno de sus cometidos esenciales. ${ }^{7}$

$\mathrm{Al}$ respecto Ferrajoli ${ }^{8}$ en lo concerniente al nexo entre garantías y justificación política externa del derecho penal apunta que:

[...] Precisamente por orientarse a regular y minimizar la violencia punitiva, las garantías se configuran como las fuentes de justificación del derecho penal [...] en contra de esta ley salvaje del más fuerte, ha sido concebido el derecho como la ley del más débil [...] este derecho se justifica sí y sólo sí, la violencia general en la sociedad, la violencia de los delitos y la violencia de las reacciones al delito, son reducidas de manera significativa [...]

tículo 18 de la Constitución Política de los Estados Unidos Mexicanos. Esta reforma constitucional reorienta la política criminal -juvenil- hacia un modelo en el que:

[...] se garanticen los derechos fundamentales que reconoce esta Constitución para todo individuo, así como aquellos derechos específicos que por su condición de personas en desarrollo les han sido reconocidos. Las personas menores de doce años que hayan realizado una conducta prevista como delito en la ley, solo serán sujetos a rehabilitación y asistencia social.

Con esta reforma se atiende a lo estipulado en el concierto internacional de naciones para orientar la política criminal destinada a los adolescentes en conflicto con la ley penal, con este sistema garantista se abandona, se deja atrás el modelo tutelar, RAMÍREZ SALAZAR, Juan Carlos "Justicia Penal para adolescentes, principios y jurisprudencia, en Revista de Derechos Humanos y Estudios Sociales, año III, no. 5, enero - junio 2011, pp 109-138, ISSN1889-8068, http://www.uaslp.mx/Spanish/Academicas/FD/REDHES/Documents/Redhes5-06.pdf, consultado 10 de junio de 2014.

4 Sin embargo de la [...] resistencia a incluir las respuestas estatales a los actos de los menores que han incurrido en conductas definidas como delitos, dentro de los asuntos político criminales [...] Tinedo, Gladys, "La política criminal en la Ley Orgánica de Protección del Niño y del Adolescente. Política criminal de menores”, Capítulo Criminológico, Vol.33, No 2, Abril-Junio 2005, 187-223, ISSN: 0798-9598.

5 Conceptualmente en dos vertientes mutuamente excluyentes: la garantista y la denominada genéricamente como derecho penal del enemigo, en los ámbitos sustantivo, adjetivo y en las consecuencias jurídicas del delito.

6 En Justicia para adolescentes en el Distrito Federal Azzolini, analiza los modelos y sistemas de justicia para adolescentes abordando puntualmente la ley de la materia para el Distrito Federal y las acciones que se llevaron a cabo para su instrumentación.

7 Si bien, en el Leviatan hobbesiano se encuentran los antecedentes remotos del contractualismo, en el que se expone la necesidad de crear, a través del contrato social, un ente supremo con autoridad tal que pueda impedir la violencia entre particulares, Locke subrayó los derechos, naturales, del individuo frente al Estado, por lo que éste se convierte en su garante y su legitimidad se supedita al cumplimiento de este cometido. En este último sentido, el neo constitucionalismo plantea, a parir de los derechos fundamentales, la responsabilidad del Estado en la disminución de la violencia, en la seguridad a los habitantes en sus bienes y en su persona y como garante de la ampliación de la esfera de derechos de las personas.

8 FERRAJOLI, Luigi, Garantismo y Derecho Penal. Un diálogo con Ferrajoli, Col. Debates de Derecho Penal, No. 5, UBIJUS-IFP, México, 2010, pp. 25-26. 


\section{EN TORNO A LA POLÍTICA CRIMINAL}

La política criminal define las conductas delictivas y los mecanismos de reacción institucional contra ellas a través del Sistema de Justicia Penal.

Los estados constitucionales fincan sus relaciones con las personas en el reconocimiento de éstas como entes autónomos, con derechos y garantías, por ello, su programa político criminal ha de estar dirigido a establecer el máximo de espacios para el ejercicio de la libertad; no puede partir de la premisa del imperativo de la norma penal y de su función motivadora, ya que esto revelaría el fracaso del contrato social y el imperio del la violencia institucionalizada, el precepto jurídico simplemente instruye o informa sobre los modelos de comportamiento y las consecuencias jurídicas esenciales, Bustos. ${ }^{9}$ En las democracias constitucionales, la política criminal no puede configurarse para limitar el ejercicio de los derechos de una persona o eliminarlo en cuanto tal..$^{10}$

El sistema penal, violento por definición, representa el talón de Aquiles de los estados democráticos, conlleva violencia sobre las personas, por tanto, una contradicción con la finalidad perseguida: libertad sin violencia, por ello, la que ejerza el Estado ha de ser la mínima necesaria en sí misma, no en relación a otra, lo que excluye por supuesto la violencia excesiva, por ejemplo: la pena de muerte, el presidio perpetuo de facto y la disminución de garantías; por el contrario, se han de privilegiar formas alternativas al control penal, no prima facie, sino ultima ratio, tales como aquéllas que permitan, regresar a los particulares los conflictos que éstos puedan resolver sin la intervención plena del aparato de justicia penal.

A raíz de las aportaciones de Rawls ${ }^{11}$ que han revitalizado el contractualismo como criterio legitimador del orden social, y de las contribuciones de Ferrajoli, ${ }^{12}$ Alexy ${ }^{13}$ y Guastini ${ }^{14}$ al constitucionalismo contemporáneo, entre otros, se han delineado, desde la filosofía del derecho y de dicho constitucionalismo, principios de una intervención penal garantista, entre los que destacan: utilidad, intervención mínima, neutralización de la víctima y mínima lesividad.

En este contexto, el reconocimiento y la efectividad de los mecanismos que hacen valer los derechos humanos se erigen como los criterios distintivos de las democracias contempo-

9 BUSTOS RAMÍREZ, Juan “Política criminal y estado”, en: Revista ciencias penales 2010, http://www.cienciaspenales.org/REVISTA\%2012/BUSTOS12.htm, febrero 2014.

10 Idem y BARATTA, Alessandro, "Requisitos mínimos del respeto de los derechos humanos en la ley penal", en: Nuevo Foro Penal, 1985.

${ }^{11}$ RAWLS, John “Justicia como equidad”, en Revista Española de Control Externo, Vol. 5, No 13, 2013 http:// dialnet.unirioja.es/servlet/articulo?codigo= 1069286, abril 2014.

12 [...] en el Estado constitucional de Derecho la Constitución no sólo disciplina las formas de producción legislativa, sino que impone también a ésta prohibiciones y obligaciones de contenido correlativas unas a los derechos de libertad y las otras a los derechos sociales, cuya violación genera antinomias o lagunas que la ciencia jurídica tiene el deber de constatar para que sean eliminadas o corregidas [...] "Pasado y futuro del Estado de Derecho", trad. Pilar Allegue, en: Neoconstitucionalismo(s), Miguel Carbonell, (Ed.), Trota, Madrid, 2005,p.18; además, op.cit., nota 3; Derechos y garantías. La ley del más débil, Madrid, Trota, 2002; El garantismo y la filosofía del Derecho, trad. Gerardo Pisarello, Alexei Julio Estada y José Manuel Díaz Martín, Serie de Teoría Jurídica y Filosofía del Derecho no. 15, Universidad Externado de Colombia, Colombia, 2001 y Derecho y razón, teoría del garantismo penal, trad. Perfecto Andrés Ibáñez, Alfonso Ruiz Miguel, Juan Carlos Bayón Mohino, Juan Terradillos Basoco, y Rocío Cantarero Bandrés, Trotta, Madrid, 1995.

${ }^{13}$ ALEXY, Robert (2005) “Los derechos fundamentales en el Estado constitucional democrático”, trad. Alonso García Figueroa, en: Neoconstitucionalismo(s), Miguel Carbonell, (Ed.), Trota, Madrid, 2005.

${ }^{14}$ GUASTINI, Ricardo "La constitucionalización del ordenamiento jurídico: el caso italiano", en: Neoconstitucionalismo(s), (Ed.), Miguel Carbonell, Trota, Madrid, 2005. 
ráneas. Así, entre los principios que caracterizan a los estados con dichas pretensiones, por su relevancia político criminal destacan: los fundamentales de la dignidad humana, los de la estructura del Estado y los de los fines del Estado social y democrático de derecho, entre los que existe una estrecha y tensa relación. ${ }^{15}$ Asimismo, cuatro tesis caracterizan la supremacía de los derechos humanos en las democracias constitucionales: i) máximo rango, ${ }^{16}$ ii) máxima fuerza jurídica, ${ }^{17}$ iii) máxima importancia del objeto ${ }^{18}$ y iv) máximo grado de indeterminación. ${ }^{19}$

Si bien la democracia se fortalece día a día por medio del reconocimiento de derechos humanos y de la creación de condiciones y mecanismos que posibiliten su ejercicio pleno, estas cuatro máximas revelan, de facto, la solides de las pretensiones constitucionales de los estados contemporáneos.

Los derechos fundamentales permean al derecho en su totalidad como juicios de valor objetivos, no obstante de las críticas por su falta de positivación, garantizan la realización plena de los fines del Estado.

\section{JUSTICIA PENAL JUVENIL}

Con el término garantismo se hace referencia a la corriente de pensamiento que parte del reconocimiento de los derechos fundamentales de las personas y de su efectiva protección como piedra angular de la arquitectura estatal y de su funcionamiento.

Al amparo de esta se ha desarrollado el análisis de los fundamentos, diseño, implementación y evaluación de la política criminal, principalmente en el ámbito de la adultez, como ya

${ }^{15}$ ALEXY, Robert, op cit, nota 10. En este texto, Alexy, menciona seis principios contemplados en el odelo alemán, contenidos en la constitución alemana, pero sólo expone cinco: i) Principios fundamentales de la dignidad humana art. 1, ii) de la libertad art. 2, iii) de la igualdad art. 3, iv) de la estructura del Estado art. 20 y v) de los fines del Estado de social y democrático de derecho art 28.1. Un artículo que se encuentra cercano a un principio fundamental es el del 20 a , Protección de los fundamentos naturales de la vida, pp. 31-36.

${ }^{16}$ Al regularse en la Constitución, en la ley máxima, por medio del principio: lex superior derogat legi inferiori, se establece una relación vinculante del derecho Constitucional con el local, confiriéndole vigencia plena, por ello, cualquier norma jurídica que lo infrinja será inconstitucional y consecuentemente nula por regla general. En la materia de tratados internacionales signados por el Estado, éstos serán norma constitucional. Previsto en el artículo 30 de la Ley Fundamental Alemana y en el artículo 133 de la Constitución Política de los Estados Unidos Mexicanos, Asimismo, la reforma constitucional en materia de derechos humanos mexicana del 10 de junio de 2011 lo puntualiza en el artículo 105, Diario Oficial de la Federación, http://dof.gob. $\mathrm{mx} /$ nota_detalle.php?codigo $=2101661 \&$ fecha $=12 /$

${ }^{17}$ Los derechos humanos son vinculantes para los ámbitos y niveles de gobierno de la administración pública y están dotados de la máxima fuerza jurídica. Para el legislativo es menester enmarcar la ley en los derechos fundamentales; para el ejecutivo se demandan líneas de acción consistentes con esto; y para el judicial, los principios constitucionales - derechos fundamentales- representan la guía de interpretación, Guastini, Ricardo, op. cit, nota 11, pp.56-57, para su aplicación posterior.

${ }^{18} \mathrm{Su}$ relevancia estriba en la regulación de derechos específicos considerados como fundamentales, por tanto objeto de protección y reconocimiento constitucional. En este mismo contexto Rawls concibe a la justicia como equidad, como un modelo democrático, como un sistema de cooperación social constituido por ciudadanos que se conciben como libres e iguales; parte de la idea de un acuerdo mutuo entre participantes que interactúan bajo condiciones equitativas de orden constitucional y político que da forma a la estructura básica de la sociedad. RAWLS, John “Justicia como equidad”, en Revista Española de Control Externo, Vol. 5, No 13, 2003, http://dialnet.unirioja.es/servlet/articulo?codigo $=106928$

${ }^{19}$ No es posible identificar los derechos fundamentales sólo en la literalidad del texto de la Carta Magna, éstos sólo se vislumbran a través de la interpretación. Los principios de la norma constitucional no se restringen al texto, son la idea general, no existe un significado único previo a la interpretación. 
se ha anotado. En el terreno de los menores, en los últimos años, en diversos países se han emprendido reformas jurídicas, que han dado lugar a las consecuentes transformaciones institucionales para hacer efectivos los derechos de los menores en conflicto con la ley penal, que en modelos anteriores no se les habían reconocido.

\section{1 ORIENTACIONES DE LA JUSTICIA JUVENIL}

La historia de la intervención penal en México ha transitado desde el correccionalismo decimonónico, pasando por el tutelarismo de la década de los setentas del siglo pasado, al garantismo reciente. ${ }^{20}$

La minoría de edad - política- ha sido concepto central de la política criminal de menores, incluso hoy sigue sin enfrentarse cabalmente, en casos límite, el problema político jurídico que ello implica. ${ }^{21}$

El correccionalismo centraba sus intervenciones en los indisciplinados, independientemente de que sus actos de rebeldía configuraran una conducta contemplada en la ley penal, así, los padres podían llevar a la correccional a los hijos incorregibles. La rebeldía se considerada como un acto de indisciplina moral y social provocada por carencias biológicas psicológicas y sociales de los sujetos, pero que por medio de un tratamiento centrado en la disciplina a través del castigo se lograría el aprendizaje de la moralidad social y con ello la corrección del individuo. Esta etapa muestra claramente el olvido y las violaciones a los derechos de los menores durante gran parte del siglo XX en México. ${ }^{22}$

El tutelarismo por su parte, también a partir de la minoridad, centró sus esfuerzos en la adaptación. La conducta de los llamados menores infractores se concibió como un problema del desarrollo; los problemas de inmadurez biológica y psicológica afectaban su proceso de socialización -introyección de normas-. Lo mismo que en el estadio anterior, ésta concepción representó una adecuación de la ideología del sistema penal de adultos.

Con este modelo, en los años setentas en México, se crea el modelo tutelar, basado en la inimputabilidad y estado de peligro del menor, excluyendo a niños y a quienes aún no cumplieran 18 años de edad del sistema de justicia penal, lo que implicó de facto una desprotección de este sector de la población, puesto que las garantías en materia penal se suprimen a

\footnotetext{
${ }^{20}$ GONZÁLEZ PLACENCIA, Luis, "Hacia un sistema penal garantista para niñ@s y adolescentes en México", Revista del Instituto de la Judicatura Federal, No. 2, enero 2002, ISSN 1405-8073, http://doctrina.vlex.com. $\mathrm{mx} / \mathrm{vid} /$ hacia-penal-garantista-adolescentes-192777313.

${ }^{21}$ En general las consecuencias del delito, tradicionalmente la pena, se han planteado para adultos, bajo el supuesto de la responsabilidad penal, como consecuencia de un acto de indisciplina política de un ciudadano. Sin embargo, en el terreno de los menores, al margen de la orientación garantista del modelo, se les somete a un proceso eminentemente penal, pero sin reconocerles su independencia política. El adulto experimenta las consecuencias de sus actos, pero tiene la posibilidad de participar en la vida política en las contiendas electorales.

Esto de ninguna manera implica la desatención de los actos definidos como delitos cometidos por menores, ni de la intervención respecto de éstos, sino examinar la consistencia interna de la política pública al respecto.

${ }^{22}$ La historia de la intervención penal en menores es un reflejo retardado de la política criminal dirigida a los adultos, las garantías reconocidas para los adultos, aunque tarde, están permeando al sistema de justicia penal juvenil.
} 
favor de su adaptación social. Ya no el castigo, regulado para los adultos, sino la adaptación indeterminada para los menores.

En este modelo resaltan, por un lado, la perdida de los límites entre el deber de asistencia y la intervención punitiva, ya que el estado de peligro $^{23}$ en el que se encuentre un menor lo convierte de facto en el momento en sujeto de tutela y faculta al estado para intervenir privándolo de su libertad, si bien en aras de su tutela, a todas luces autoritariamente. ${ }^{24}$ Por otro lado, la perspectiva de adaptación social supone un proceso fundamentalmente clínico, en el que el centro de atención es la personalidad del sujeto, su ser en sí, no la lesión a bienes jurídicos tutelados penalmente o respecto de la magnitud de ésta. ${ }^{25}$

En México, el tránsito hacia una concepción garantista del sistema penal juvenil es posible identificarlo en la reforma de 1991, que en contraste con la reforma de 1974 represento un avance, mínimo pero avance al fin. Al respecto, González ${ }^{26}$ inicialmente comparó los modelos inspirados en las reformas de 1974 y $1991^{27}$ a través de 11 criterios y posteriormente los cotejó con los principios de una intervención garantista. Así:

i) La concepción del sistema, la ley del 91 no obstante de ser inspirada predominantemente por una orientación asistencial incorpora elementos formalmente garantistas, mientras que la de 74 es eminentemente asistencial;

ii) La concepción del menor continúa centrada en la inimputabilidad y la consecuente irresponsabilidad, igual que en la ley anterior;

iii) Concepción del delito, en la ley de 1991, se establecen faltas administrativas, que en el caso de adultos constituirían delitos, mientras que en la ley previa, la de 74, existía una frontera difusa entre estado de peligro y faltas administrativas;

iv) Los criterios de investigación, en la ley del 91 incorpora la seguridad jurídica, pues es necesaria la comisión de faltas, delitos en el caso de adultos, mientras que en la ley del 74 bastaba acreditar el estado de peligro;

v) La concepción del castigo, en ambas legislaciones están presentes, formalmente, sólo las medidas de seguridad;

vi) La duración de las sanciones en la ley del 91 se determina con base en los límites máximos, sin embargo no considera un criterio de proporcionalidad respecto de la ponderación al bien jurídico y a la magnitud de la lesión respectiva, sin embargo es una avan-

\footnotetext{
${ }^{23}$ Por ejemplo, el Código de Procedimientos Penales del Estado de Oaxaca, en el artículo 509 otorgaba competencia al Consejo Tutelar, para intervenir en los casos de los menores que hagan presumir fundadamente su inclinación a causar daño a sí mismos, a su familia o a la sociedad [...], Vasconcelos Méndez, Rubén, La justicia para adolescentes en México. Análisis de las leyes estatales, Instituto de Investigaciones Jurídicas, Serie Doctrina Jurídica, No. 49o, Universidad Nacional Autónoma de México, Fondo de las Naciones Unidas para la Infancia, México. 2009, p.9.

${ }^{24}$ GONZÁLEZ PLACENCIA, Luis, Op.Cit, nota 17.

${ }^{25}$ Idem.

${ }^{26}$ GONZÁLEZ PLACENCIA, Luis (2006) “Justicia penal para adolescentes en conflicto con la ley penal”, Iter Criminis, Revista de Ciencias Penales, Núm. 3, tercera época, 2006, pp. 89-126

27 En adelante ley del 74 y ley del 91, respectivamente. 
ce respecto de la ley de 74 que por basarse en medidas terapéutica, la intervención era indeterminada;

vii) El derecho a la defensa, ausente en la ley del 74 se encuentra presente en la del 91, destinada a la verificación de la comisión de la falta imputada, siguiendo un modelo inquisitorial;

viii) Los mecanismos para justificar la intervención estatal se desprendes, en la ley del 74 de la evaluación de la personalidad del menor y de su estado de peligro, realizada por un órgano colegiado técnico, mientras que en la del 91, se desprende de la sujeción a un proceso;

ix) Mecanismos para validar la imposición de la intervención esencialmente son iguales, puesto que en la ley del 74 se desprenden de la resolución del comité técnico respecto de la peligrosidad o estado de peligro del adolescente, mientras que en la del 91 de la evaluación de la personalidad del menor, realizada ésta también por un comité técnico;

x) El límite de la edad penal, en ambas legislaciones es el criterio para determinar a sujeción del sujeto a uno u otro sistema, tutelar o penal en la ley de 74 y sistema de menores o penal en la del 91; finalmente,

xi) La relación con el sistema penal es independiente en ambas legislaciones.

Como se desprende de lo anterior, si bien la ley del 91 representó un avance respecto de su homóloga del 74, aún conservaba una esencia eminentemente asistencial. Asimismo, de estas dos reformas, sólo la del 91 se apego, en alguna medida a principios garantistas. ${ }^{28}$ Tres principios están ausentes:

i) La culpabilidad no está presente, pues la medida se funda en el diagnóstico de personalidad del autor y no en el acto;

ii) La jurisdiccinalidad, ya que el consejo de menores está fuera de ésta y,

iii) Verificación, ya que por la naturaleza del procedimiento la carga de la prueba queda en la defensa.

Cuatro se encuentras contemplados parcialmente: i) necesidad, ii) lesividad, y iii) materialidad en la medida que se remite al código penal, y iv) contradicción, no obstante su notoria desventaja respecto de la acusación.

Finalmente, tres principios se encuentran plenamente presentes: i) retribución, puesto que la medida impuesta es un acto tipificado en la ley penal, ii) legalidad, se distingue entre niños y adolescentes y de éstos últimos aquéllos que requieren asistencia de los que cometieron conductas contempladas en la legislación penal y iii) acusatorio, existe un funcionario

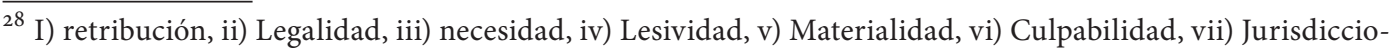
nalidad, viii) Acusoatorio, ix) verificación y x) contradicción.
} 
que realiza la acusación. ${ }^{29} \mathrm{Al}$ respecto, Manuel Vidaurri ofrece un interesante examen de los principios orientadores del sistema. ${ }^{30}$

\section{III.2. MODELO DE RESPONSABILIDAD PENAL JUVENIL}

La implementación del modelo de responsabilidad penal se implementó en México a raíz de la reforma constitucional realizada en 2005. Con esta reforma se sentaron las bases para crear un nuevo sistema integral de justicia para adolescentes en conflicto con la ley penal.

El sistema de responsabilidad juvenil o de responsabilidad penal para adolescentes es un conjunto de normas e instituciones creadas exprofeso para dar respuestas a la situación de las personas menores de edad imputadas o encontradas responsables de la comisión delitos, ${ }^{31}$ por lo que se es posible considerarlo cono parte de la política criminal.

El modelo parte del reconocimiento de los menores como sujetos titulares de derechos y obligaciones, de la responsabilidad de menor, en el ámbito de la competencia de la legislación especial creada ex profeso en atención a su estado de desarrollo.

Las pretensiones de esta estrategia de política criminal juvenil están orientadas a proteger los derechos fundamentales, frente a ejercicio punitivo del Estado, a minimizar la violencia de la reacción ante el delito. ${ }^{32}$

El sistema se concibe como [...] un derecho penal, estos es, de control social, que establece un marco de garantías jurídico penales frente al poder punitivo del Estado [...], ${ }^{33}$ no obstante no todas las legislaciones locales lo han entendido así, por ejemplo:

[...] el Código de Justicia para Adolescentes del Estado Libre y soberano de Puebla señala que su objeto es establecer las base de 'un sistema integral de justicia y asistencia social' (artículo 1..) y la Ley de Justicia para Menores del estado de Querétaro concibe que el sistema integral de justicia para menores 'comprende la rehabilitación y la asistencia social' $[\ldots] \cdot{ }^{34}$

Como puede apreciarse, caminos distintos siguen la reflexión teórica, las directrices generales de política criminal y las legislaciones estales, respecto de los operadores, queda aún por esperar.

\section{CONSIDERACIONES FINALES}

Indudablemente el modelo de responsabilidad juvenil representa un avance importante en la materia y evidencia un cambio de orientación en el tratamiento político criminal de la responsabilidad de los menores.

Por otro lado, si bien, responder por las consecuencias de los actos propios es un proceso por el que el menor transita, la responsabilidad penal, al margen de sus consecuencias, está

\footnotetext{
${ }^{29}$ GONZÁlEZ PLACENCIA, Luis, Op.Cit, nota 23.

${ }^{30}$ VIDAURRI ARÉCHIGA, Manuel, "Notas emergentes en torno a los principios orientadores del nuevo sistema de justicia penal de menores, en: Estudios jurídicos en homenaje a Olga Islas de González Mariscal, Sergio García Ramírez, Coord., Universidad Nacional Autónoma de México, 2007.

${ }^{31}$ VASCONCELOS MÉNDEZ, Rubén, Op.Cit. nota 20, p 7-8.

32 FERRAJOLI, Luigi, Op.Cit, nota 5, pp. 25-26.

33 VASCONCELOS MÉNDEZ, Rubén, Op.Cit. nota 2o, p 20.

34 Idem. 
vinculada con el ejercicio político, por lo menos con el sufragio, del que está excluido el menor, por lo que es necesario generar modelos de responsabilidad ad hoc a la problemática inherente a la denominada justicia penal juvenil, en los que se minimicen las inconsistencia político-jurídicas existentes en los modelos existentes y posibiliten una reacción institucional más consistente con los principios de las democracias contemporáneas.

V. FUENTES

ALEXY, Robert (2005) "Los derechos fundamentales en el Estado constitucional democrático", trad. Alonso García Figueroa, en: Neoconstitucionalismo(s), Miguel Carbonell, (Ed.), Trota, Madrid.

AZZOLINI BIANCAS, Alicia B., "La Justicia para Adolescentes en el Distrito Federal”, en Alegatos, 76, septiembre-diciembre México 2010.

BARATTA, Alessandro (1985), "Requisitos mínimos del respeto de los derechos humanos en la ley penal", en: Nuevo Foro Penal.

BUSTOS RAMÍREZ, Juan (2010) “Política criminal y estado", en: Revista ciencias penales,http://www.cienciaspenales.org/REVISTA\%2012/BUSTOS12.htm.

FERRAJOLI, Luigi (2010) Garantismo y Derecho Penal Un diálogo con Ferrajoli, No. 5 Col. Debates de Derecho Penal, UBIJUS-IFP, México.

(2005) "Pasado y futuro del Estado de Derecho", trad. Pilar Allegue, en: Neoconstitucionalismo(s), Miguel Carbonell, (Ed.), Trota, Madrid.

(2002) Derechos y garantías. La ley del más débil, Madrid, Trota.

(2001) El garantismo y la filosofía del Derecho, trad. Gerardo Pisarello, Alexei Julio Estada y José Manuel Díaz Martín, Serie de Teoría Jurídica y Filosofía del Derecho no. 15, Universidad Externado de Colombia, Colombia.

(1995) Derecho y razón, teoría del garantismo penal, trad. Perfecto Andrés Ibáñez, Alfonso Ruiz Miguel, Juan Carlos Bayón Mohino, Juan Terradillos Basoco, y Rocío Cantarero Bandrés, Trotta, Madrid.

GONZÁLEZ PLACENCIA, Luis (2006) "Justicia penal para adolescentes en conflicto con la ley penal”, Iter Criminis, Revista de Ciencias Penales, Núm. 3, tercera época, 89126.

(2002) “Hacia un sistema penal garantista para niñ@s y adolescentes en México", Revista del Instituto de la Judicatura Federal, No 2, enero 2002, ISSN 1405-8073, http://doctrina.vlex.com. mx/vid/hacia-penal-garantista-adolescentes-192777313.

GUASTINI, Ricardo (2005) "La constitucionalización del ordenamiento jurídico: el caso italiano”, en: Neoconstitucionalismo(s), (Ed.), Miguel Carbonell, Trota, Madrid.

HOBBES, Thomas (2003) Leviatán, Losada, Argentina.

LOCKE, John (2005) Ensayos sobre el gobierno civil, Porrúa, México. 
MENDOZA BAUTISTA, Katherine (2009) 20 derechos de la Niñez ante el Ministerio Público, No. 3, Col. Investigación Ministerial, UBIJUS-IFP, México.

RAMÍREZ SALAZAR, Juan Carlos "Justicia Penal para adolescentes, principios y jurisprudencia, en Revista de Derechos Humanos y Estudios Sociales, año III, no. 5, enero - junio 2011, pp 109-138, ISSN1889-8068, http://www.uaslp.mx/Spanish/Academicas/ FD/REDHES/Documents/Redhes5-06.pdf, consultado 10 de junio de 2014.

RAWLS, John (2003) “Justicia como equidad”, en Revista Española de Control Externo, Vol. 5, No 13, http://dialnet.unirioja.es/servlet/articulo?codigo $=1069286$.

SECRETARÍA DE GOBERNACIÓN (12/12/2005) Decreto por el que se reforma el párrafo cuarto y se adicionan los párrafos quinto y sexto y se recorren en su orden los últimos párrafos del Artículo 18 de la Constitución Política de los Estados Unidos Mexicanos, Diario Oficial de la Federación, Primera sección, http://dof.gob.mx/nota_detalle. php?codigo $=2101661 \&$ fecha $=12 / 12 / 2005$.

TINEDO, Gladys (2005) "La política criminal en la Ley Orgánica de Protección del Niño y del Adolescente. Política criminal de menores”, Capítulo Criminológico, Vol. 33, No 2, Abril-Junio 2005, 187-223, ISSN: 0798-9598.

VASCONCELOS MÉNDEZ, Rubén (2009) La justicia para adolescentes en México. Análisis de las leyes estatales, Instituto de Investigaciones Jurídicas, Serie Doctrina Jurídica, No. 490, Universidad Nacional Autónoma de México, Fondo de las Naciones Unidas para la Infancia, México.

VIDAURRI ARÉCHIGA, Manuel, "Notas emergentes en torno a los principios orientadores del nuevo sistema de justicia penal de menores, en: Estudios jurídicos en homenaje a Olga Islas de González Mariscal, Sergio García Ramírez, Coord., Universidad Nacional Autónoma de México, 2007. 